\title{
Bioethanol from corn stover - Integrated environmental impacts of alternative biotechnologies
}

\author{
Zhao, Yan; Damgaard, Anders; Liu, Shan; Chang, Huimin; Christensen, Thomas Højlund
}

Published in:

Resources, Conservation and Recycling

Link to article, DOI:

10.1016/j.resconrec.2019.104652

Publication date:

2020

Document Version

Peer reviewed version

Link back to DTU Orbit

Citation (APA):

Zhao, Y., Damgaard, A., Liu, S., Chang, H., \& Christensen, T. H. (2020). Bioethanol from corn stover Integrated environmental impacts of alternative biotechnologies. Resources, Conservation and Recycling, 155, [104652]. https://doi.org/10.1016/j.resconrec.2019.104652

\section{General rights}

Copyright and moral rights for the publications made accessible in the public portal are retained by the authors and/or other copyright owners and it is a condition of accessing publications that users recognise and abide by the legal requirements associated with these rights.

- Users may download and print one copy of any publication from the public portal for the purpose of private study or research.

- You may not further distribute the material or use it for any profit-making activity or commercial gain

- You may freely distribute the URL identifying the publication in the public portal 
4 Bioethanol from corn stover - Integrated environmental impacts of 5 alternative biotechnologies

6

7 Yan Zhao a, Anders Damgaard ${ }^{\text {b }}$, Shan Liu ${ }^{a}$, Huimin Chang a and Thomas H. Christensen ${ }^{\text {b,* }}$ 8

9 a School of Environment, Beijing Normal University, Beijing 100875, China

10 b Department of Environmental Engineering, Technical University of Denmark, Kgs.

11 Lyngby 2800, Denmark

12

13 First author: Yan Zhao, yanzhao@bnu.edu.cn

14 Corresponding author: Thomas H. Christensen, thho@env.dtu.dk

15 


\section{Abstract}

17 The environmental impact potentials of producing bioethanol from corn stover were systematically assessed

18 by life cycle assessment using datasets reported in the literature. The $15 \%$ best datasets with respect to 19 global warming potential for seven different technological configurations were extracted from a published 20 database reviewing 474 publications on converting corn stover to bioethanol. A total of 10 impact categories 21 were evaluated. The impacts included both environmental loads and savings, and generally ranged from $22-0.1$ to 0.1 person-equivalent per ton of dry corn stover for most non-toxic impacts and -0.2 to 0.5 person23 equivalent for toxic impacts. Fossil fuel substitution with bioethanol provided savings in most impact 24 categories, and so did the energy recovered from the residues, while enzyme production was a significant 25 load. The treatment and discharge of effluent from the liquid residues may constitute a significant load to 26 the environment. Based on the cumulative probabilities of overall environmental performance together with 27 the bioethanol amount produced, the prioritisation of technologies for further development should be as 28 follows: steam explosion (S4) and ammonia-based (S6) technologies as the highest priorities with 29 approximately $100 \%$ and $40 \%$ probabilities to have savings in non-toxic and toxic impacts, respectively; 30 acid (S1), alkaline (S2) and fungi (S7) technologies as medium priorities and solvent-based (S3) and liquid 31 hot water (S5) technologies have the lowest priorities. We suggest the integration of life cycle assessment 32 modelling to the research and development of biofuel production from biomass waste to ensure that the 33 technologies being developed for full-scale applications are sustainable.

\section{Keywords}

36 bioethanol; life cycle assessment; integrated environmental impacts; probability analysis; sustainability 37 quantification; corn stover 


\section{Introduction}

Bioethanol is used as green fuel in many countries, such as the USA, Brazil and India (Morales et al., 2015, Soam et al., 2016, Wojtusik et al., 2016). It is often used as an amendment to gasoline to reduce the fossil content of the fuel and thereby lessen the global warming impact of transportation. To date, nearly all bioethanol is produced by first-generation biotechnologies using corn, sugarcane or molasses as feedstocks (Zabed et al., 2016). Given that these types of feedstocks are either grown primarily for producing bioethanol or could have served as animal fodder, their label of being green and contributing to savings in fossil $\mathrm{CO}_{2}$ emissions has been severely questioned (Jung et al., 2017, Abo et al., 2019). This has led to interest in using waste such as agricultural residues for producing bioethanol, and significant savings in global warming potential have been supposed when compared to fossil fuels (Dutta et al., 2014, Chang et al., 2017). Using corn stover, the residue generated by corn processing, has gained great interest in the field of bioethanol production because of its availability in very large quantities and at low costs, though corn stover has also been partly used for tilling down or as animal fodder. However, the technologies for producing bioethanol from corn stover are primarily at the experimental level (Zhao et al., 2018); the literature barely revealed any scientific reports on full scale plants in operation (Zhao et al., 2018). The challenge is that the corn stover is not easily converted to bioethanol because of its structure and high lignin content, and many approaches have been reported on how to pretreat and hydrolyse corn stover prior to saccharification and fermentation to bioethanol (Loow et al., 2016).

Several pretreatment processes have been developed and investigated for the disruption of lignocellulosic structures in order to make the polysaccharides available for further conversion (SolarteToro et al., 2019). This includes physical, chemical, biological and other processes (Capolupo and Faraco, 2016, Kumar et al., 2016). However, given the overall aim of supporting sustainable development by substituting fossil fuels with bioethanol and thereby reducing greenhouse gas emissions from the transport sector, balancing of the ethanol production and the overall environmental performance including global warming potential is crucial for technology selection and optimisation. Life cycle assessment (LCA) has been acknowledged as an effective approach for addressing the potential environmental impacts of the technological management systems for products, services and solid waste. In recent years, many studies have conducted LCA on systems of bioethanol production with specific focuses, including different feedstocks (Chang et al., 2017, Rathnayake et al., 2018), typical conversion technologies (Zhu et al., 2015, Mandegari et al., 2017, Olofsson et al., 2017) and local biorefinery strategies (Farahani and Asoodar, 2017,

69 Zucaro et al., 2018). However, relevant studies often investigated only one or few technologies for 70 converting lignocellulosic waste to bioethanol (Hong et al., 2015, Guerrero and Munoz, 2018). In many cases, the studied LCA systems did not cover the full processes including pretreatment, hydrolysis, fermentation and ethanol substitution; in addition, only one dataset or inconsistent data sources for 
74 technologies for converting corn stover to bioethanol, residue treatment and estimating the uncertainty and robustness are critical and a prerequisite for comparison of technologies (Bairamzadeh et al., 2018). These aspects have been involved in only few studies (Pourhashem et al., 2013, Murphy and Kendall, 2015). Despite the many papers addressing the environmental impacts and uncertainties of bioconversion technologies for cellulosic bioethanol production (Spatari et al., 2010, Neupane et al., 2017), the current literature leaves a very scattered picture of which technologies for cellulosic bioethanol production are most successful in ethanol production and environmental performance given the significant variations in technical approaches and process parameters (Zhao et al., 2019).

After reviewing 474 scientific publications on corn stover conversion to bioethanol, Zhao et al. (2019) recently determined the global warming potential of 141 research-based datasets with relatively high completeness and/or consistency on producing bioethanol from corn stover, including upstream contributions (electricity, chemicals, enzymes, etc.), energy use and process emission during bioethanol production as well as savings obtained from utilising the residues for energy purposes and from bioethanol substituting for fossil gasoline. The experimental datasets were grouped into seven technological configurations according to the pretreatment approaches (acid, alkaline, solvent-based, steam explosion, liquid hot water, ammonia-based and fungi). Interestingly, only half of the datasets would provide savings in global warming potential. Moreover, when the energy recovery from solid and liquid residues was not included, only a quarter of the datasets provided savings in global warming. This suggested that not only selecting the right technology (which pretreatment to use) but also optimising the individual technology is important. Zhao et al. (2019) modeled global warming potentials by parametrising all key processes and establishing statistical distributions of the key parameters based on the reported data. This method enabled focusing on the best datasets, and considering the data representing the $15 \%$ best cases for each technology in terms of providing savings in global warming, Zhao et al. (2019) concluded that steam explosion and ammonia-based pretreatment statistically were the most promising technologies for converting $18 \%-22 \%$ of the corn stover into bioethanol (dry weight) and providing potential global warming savings of 850 $1050 \mathrm{~kg} \mathrm{CO}$-equivalence per $1000 \mathrm{~kg}$ of dry corn stover.

Savings in global warming contribution when producing bioethanol for substituting fossil fuels is a key environmental issue, and this issue was addressed by Zhao et al. (2019). However, to address sustainability in a broad context, all potential environmental impacts must be addressed. This aspect is particularly important to bioethanol production from corn stover because experimentally documented pretreatment technologies are considerably different in terms of approach and energy, chemical and enzyme consumption. These technologies all have highly variable environmental rucksacks associated with their production processes. This work provides for the first time a stringent LCA considering 10 potential environmental impacts of seven different technologies for producing bioethanol from corn stover. We conduct the LCA on the large dataset reported by Zhao et al. (2018) and the statistical parameter distributions extracted from the 141 most consistent datasets by Zhao et al. (2019). We focus on the $15 \%$ 
110 best datasets within each technology with respect to global warming potential (GWP) established by Zhao

111 et al. (2019), because we acknowledge that the key experimental parameters vary significantly and we do

112 believe that technology development is always focusing on the best performing solutions. Here 'best' means

113 providing the largest savings in GWP, which does not necessarily mean yielding the highest bioethanol

114 output. The LCA study provides a thorough assessment of biorefinery technologies under development in

115 terms of ethanol produced per ton corn stover and environmental impact potentials in global warming,

116 acidification, nutrient enrichment, photochemical ozone formation, particulate matter, ecotoxicity and

117 human toxicity. In addition, the process contribution to the impacts, the global sensitivity analysis of

118 parameters and the probability analysis of integrated impact potentials were performed to provide

119 comprehensive understandings on the alternative biotechnologies. The size and quality of the parametrised

120 datasets established allow us to provide estimates of the robustness of the quantifications and an analysis

121 of the most sensitive parameters governing the environmental aspects of producing bioethanol from corn

122 stover. This contribution provides unprecedented quantitative insights into the technologies being

123 developed for producing bioethanol from corn stover.

2. Approach and methods

\section{6}

127

128

129

\subsection{Technological configurations and model system}

Typical biotechnological configurations for converting corn stover to ethanol were identified in our previous review as combinations of pretreatment, hydrolysis, fermentation and purification (Zhao et al., 2018). According to the pretreatment step, the seven technological configurations involved in this study are briefly illustrated in Figure 1. The details are provided in a previous work (Zhao et al., 2018).

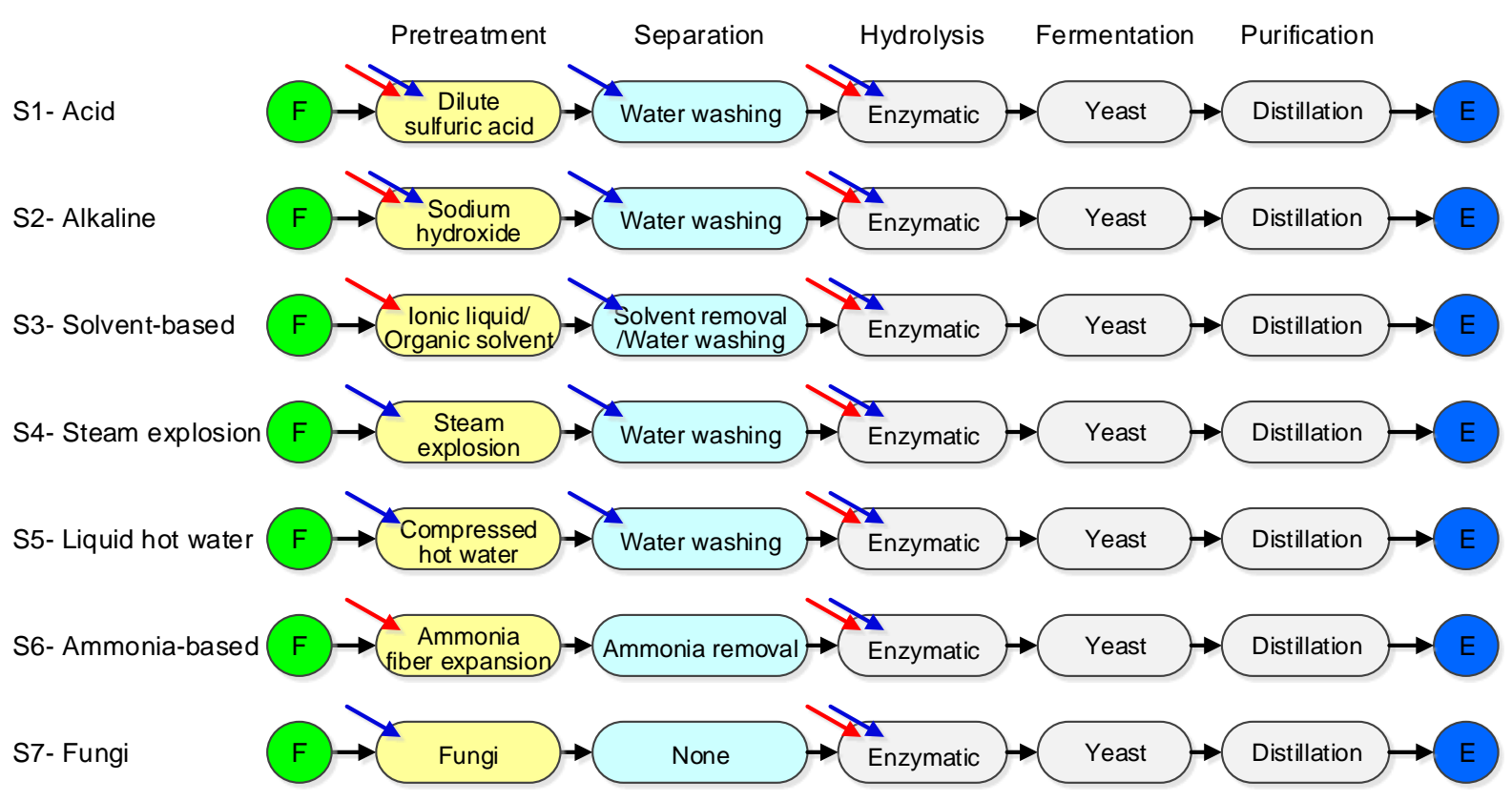

Figure 1. Main processes of the seven technological configurations for producing ethanol from corn stover (F: feedstock, i.e. corn stover; E: ethanol produced. The red arrows indicate the addition of chemicals 
or enzymes; the blue arrows indicate water addition. The side streams for liquid and solid residue treatment are included in the life cycle system but not shown here.).

For the assessment of the integrated environmental impacts of the seven identified technological configurations, the technological systems for producing ethanol from corn stover were established as described in our previous study, and the functional unit was defined as the 'biorefinery of $1 \mathrm{t}(1000 \mathrm{~kg}$ dry matter) of corn stover with bioethanol as the major product' (Zhao et al., 2019). The system boundary includes the collection, transportation and mechanical preparation of the corn stover, all the major processes of bioethanol production (including use of water, chemicals, enzymes and energy), the treatment of solid and liquid residues (including water, heat and power recovery from incineration and anaerobic digestion) and the downstream use of the produced ethanol (system diagram shown in the Supplementary Information) (Zhao et al., 2019). All the details of process description and system assumptions including ethanol substitution, energy consumption in common processes and treatment of liquid and solid residues are provided in a previous work (Zhao et al., 2019).

\subsection{Modelling tool and method for life cycle impact assessment}

LCA was performed with EASETECH, a specialised LCA model for assessing the environmental technologies of complex systems handling heterogeneous material flows (Clavreul et al., 2014). The method for life cycle impact assessment used in this study was in accordance with the recommendation of the International Reference Life Cycle Data System (ILCD) Handbook and considered the following impact categories: climate change (global warming potential), stratospheric ozone depletion, acidification, eutrophication (terrestrial), eutrophication (freshwater), eutrophication (marine), photochemical ozone formation (human health), ecotoxicity (freshwater), human toxicity (cancer effects), human toxicity (noncancer effects), particulate matter, ionizing radiation (human health), and abiotic resource depletion (fossil and mineral). Land use and resource depletion of water were not included because of the strong geographical uncertainty; abiotic resource depletion (fossil and mineral) was also not included because of its irrelevance (mineral) and partial coverage in climate change (fossil). For comparison across categories, the results in this study were expressed in personal equivalents whereby the results are normalised by the annual impact from an average person. The normalisation factors of all the impact categories of the ILCD methods are listed in Table 1 (Laurent et al., 2013). Given the different recommendation levels of the impact categories on the basis of the quality of the characterisation model for each impact category (Hauschild et al., 2013), the results in this study are presented in terms of non-toxic and toxic categories separately.

The modelling was carried out as an attributional LCA. In addition, life cycle inventory data for background processes, including chemicals, heat, electricity and fuel production, were mainly selected from the Ecoinvent database (allocation at the point of substitution) (Ecoinvent, 2016). Global processes were used where possible because the study does not apply to any specific region. For processed used in multiple 
scenarios, we employed the same process across the different scenarios. The details are found in (Zhao et al., 2019).

Table 1 Normalisation factors and impact categories of the ILCD methods used in this study (Hauschild et al., 2013, Laurent et al., 2013)

\begin{tabular}{|c|c|c|c|}
\hline ILCD Impact category & Unit & $\begin{array}{l}\text { Normalisation } \\
\text { factor }\end{array}$ & $\begin{array}{l}\text { Recommendation } \\
\text { level* }\end{array}$ \\
\hline Climate change & $\mathrm{kg} \mathrm{CO} 2$ eq./PE/year & $8.10 \times 10^{+03}$ & I \\
\hline Stratospheric ozone depletion & kg CFC-11 eq. /PE/year & $4.14 \times 10^{-02}$ & I \\
\hline Acidification & mol H+ eq. $/ \mathrm{PE} /$ year & $4.96 \times 10^{+01}$ & II \\
\hline Eutrophication (terrestrial) & mol $\mathrm{N}$ eq. $/ \mathrm{PE} /$ year & $1.15 \times 10^{+02}$ & II \\
\hline Eutrophication (freshwater) & $\mathrm{kg} \mathrm{P}$ eq. $/ \mathrm{PE} /$ year & $6.20 \times 10^{-01}$ & II \\
\hline Eutrophication (marine) & $\mathrm{kg} \mathrm{N}$ eq. $/ \mathrm{PE} /$ year & $9.38 \times 10^{+00}$ & II \\
\hline $\begin{array}{l}\text { Photochemical ozone formation } \\
\text { (human health) }\end{array}$ & kg NMVOC eq. /PE/year & $5.67 \times 10^{+01}$ & II \\
\hline Ecotoxicity (freshwater) & CTUe/PE/year & $6.65 \times 10^{+02}$ & II/III \\
\hline Human toxicity (cancer effects) & CTUh/PE/year & $5.42 \times 10^{-05}$ & $\mathrm{II} / \mathrm{III}$ \\
\hline $\begin{array}{l}\text { Human toxicity (non-cancer } \\
\text { effects) }\end{array}$ & CTUh/PE/year & $1.10 \times 10^{-03}$ & II/III \\
\hline Particulate matter & kg PM2.5 eq. /PE/year & $2.76 \times 10^{+00}$ & $\mathrm{I} / \mathrm{II}$ \\
\hline Ionising radiation (human health) & $\begin{array}{l}\mathrm{kBq} \mathrm{U}^{235} \text { eq. (to air) } \\
/ \mathrm{PE} / \text { year }\end{array}$ & $1.33 \times 10^{+03}$ & II \\
\hline
\end{tabular}

* Recommendation level: I, recommended and satisfactory; II, recommended but in need of some improvements; III, recommended, but to be applied with caution (Hauschild et al., 2013).

\subsection{Key process parameters and data distribution}

To evaluate and compare the integrated environmental impacts of different technological configurations, a parameterisation approach was applied to provide consistent flows (mass, solids, key substrates and water) and material and energy accounts. A set of parameters was identified for the seven technological configurations and used as input in the modelling in accordance with (Zhao et al., 2019). The parameter descriptions are listed in Table 2 .

In our previous work on global warming footprint of alternative biotechnologies for bioethanol production from corn stover, the probability distribution of each parameter was obtained on the basis of the 184141 individual datasets with relatively high completeness and consistency selected from 474 publications (Zhao et al., 2019). The data quality and completeness were reported in Zhao et al. (2018, 2019). From 
were identified to represent potential targets for improving the technologies of each configuration. The key parameters identified from global sensitivity analysis can be optimised according to the parameter probability distribution in the top $15 \%$ 'best-GWP' cases.

Table 2 Parameters used in modelling the technological configurations for the bioconversion of corn stover into ethanol

\begin{tabular}{|c|c|c|c|}
\hline Classification & Parameter & Unit & Description \\
\hline \multirow[t]{5}{*}{ Raw material composition } & GPP_RM & $\% \mathrm{TS}$ & Glucan proportion in raw materials \\
\hline & $\mathrm{XPP}^{-} \mathrm{RM}$ & $\% \mathrm{TS}$ & Xylan proportion in raw materials \\
\hline & LPP_RM & $\% \mathrm{TS}$ & Lignin proportion in raw materials \\
\hline & APP_RM & $\% \mathrm{TS}$ & Ash proportion in raw materials \\
\hline & OPP_RM & $\% \mathrm{TS}$ & Other proportion in raw materials \\
\hline \multirow[t]{4}{*}{ Solid loading } & SL_PT & $\%$ wt & Total solid content in $\mathrm{PT}^{*}$ \\
\hline & SL_PW & $\%$ wt & Total solid content in post-wash \\
\hline & $\mathrm{SL}_{-}^{-} \mathrm{HL}$ & $\% w t$ & Total solid content in HL* \\
\hline & $\mathrm{SL} \mathrm{FT}$ & $\%$ wt & Total solid content in FT* \\
\hline \multirow[t]{7}{*}{ Conversion coefficient } & GEF PT & $\%$ & Glucan yield to solid phase in PT \\
\hline & GEF_HL & $\%$ & Glucose yield to liquid phase in HL \\
\hline & GEF_FT & $\%$ & Ethanol yield from glucose in FT \\
\hline & XEF_PT & $\%$ & Xylan yield to solid phase in PT \\
\hline & XEF_HL & $\%$ & Xylose yield to liquid phase in HL \\
\hline & XEF_FT & $\%$ & Ethanol yield from xylose in FT \\
\hline & LEF_PT & $\%$ & Lignin yield to solid phase in PT \\
\hline \multirow[t]{8}{*}{ Operational condition } & T PT & ${ }^{\circ} \mathrm{C}$ & Reaction temperature in PT \\
\hline & $\overline{\mathrm{MS}} \mathrm{PT}$ & Rpm & Mixing speed in PT \\
\hline & $\mathrm{MS}^{-} \mathrm{HL}$ & Rpm & Mixing speed in HL \\
\hline & MS_FT & Rpm & Mixing speed in FT \\
\hline & RT_PT & $\mathrm{H}$ & Reaction time in PT \\
\hline & $\mathrm{RT}_{-}^{-} \mathrm{HL}$ & $\mathrm{H}$ & Reaction time in HL \\
\hline & RT_FT & $\mathrm{H}$ & Reaction time in FT \\
\hline & $\mathrm{PS}$ & & Pretreatment severity \\
\hline \multirow[t]{3}{*}{ Material consumption } & CC_PT & $\mathrm{kg} / \mathrm{kg}$ & Chemical consumption in PT \\
\hline & CR_PT & & Chemical recovery ratio in $\mathrm{PT}$ \\
\hline & BA_HL & $\mathrm{kg} / \mathrm{kg}$ & Enzyme consumption in HL \\
\hline \multirow[t]{6}{*}{ Energy consumption } & EC_PT & $\mathrm{kWh} / \mathrm{kg}$ & Electricity consumption in $\mathrm{PT}$ \\
\hline & $\mathrm{HC}_{-}^{-} \mathrm{PT}$ & $\mathrm{MJ} / \mathrm{kg}$ & Heat consumption in $\mathrm{PT}$ \\
\hline & $\mathrm{EC}-\mathrm{HL}$ & $\mathrm{kWh} / \mathrm{kg}$ & Electricity consumption in $\mathrm{HL}$ \\
\hline & $\mathrm{HC}_{-}^{-} \mathrm{HL}$ & $\mathrm{MJ} / \mathrm{kg}$ & Heat consumption in HL \\
\hline & $\mathrm{EC}_{-} \mathrm{FT}$ & $\mathrm{kWh} / \mathrm{kg}$ & Electricity consumption in FT \\
\hline & $\mathrm{HR}{ }^{-} \mathrm{PT}$ & $\mathrm{MJ} / \mathrm{kg}$ & Heat recovery in $\mathrm{PT}$ \\
\hline
\end{tabular}

* PT, HL, and FT stand for pretreatment, hydrolysis, and fermentation, respectively. reduction is of the highest priority in substituting fossil fuel. In this study investigating the integrated environmental impacts of alternative technologies with the best GWP performance, a specific probability distribution of each parameter was adopted on the basis of the parameter values of the top 15\% 'best-GWP' cases. Normal (ND), lognormal (LD), uniform (UD) and triangular (TD) distributions were implemented 
model (Bisinella et al., 2016). The cumulative distribution and fitting curve of each parameter in each

201 technological configuration are shown in the Supplementary Information. The corn stover composition was

202 identical across the technological configurations as follows: glucan $36.2 \% \pm 3.2 \%$, xylan $22.7 \% \pm 4.2 \%$,

203 lignin $18.5 \% \pm 3.7 \%$, ash $5.0 \% \pm 2.7 \%$ and others $17.6 \% \pm 7.9 \%$ (Zhao et al., 2019 ).

\subsection{Statistical approach and global sensitivity analysis}

Based on the parameter distribution obtained from the top 15\% 'best-GWP' cases, Monte Carlo method was implemented in EASETECH to randomly sample 5000 values within each parameter distribution and calculate the environmental impact results of each scenario. Apart from the statistical data including average value and deviation, the calculated results were further used to present the uncertainty describing the overall variation and the robustness of the results (Mullins et al., 2011) by constructing a frequency histogram and computing a probability distribution within a 95\% confidence level (Zhao et al.,

213 Discernibility analysis was performed accordingly to show statistically how frequently one technology is

214 better than another when both technologies are subject simultaneously to the same variations in common 215 parameters (Bisinella et al., 2016). Priority classification was then provided for all the studied technologies 216 according to their sustainability performance from a probability perspective, supplemented by 217 considerations on the ethanol production.

Sensitivity was expressed by the sensitivity ratio calculated for each parameter in each scenario, by changing one parameter by $1 \%$ once at a time while keeping all the other parameters fixed at their basic values (Bisinella et al., 2016). The mode values calculated from the distribution of each parameter were used as the basic values of the tested parameters in sensitivity analysis. The global sensitivity analysis (also known as global importance analysis), which includes an analysis of the fundamental connections between the sensitivity and the uncertainty of individual parameters, was applied to present the contribution of each independent parameter to the result variance (Bisinella et al., 2016).

\subsection{Scenario sensitivity analysis with different wastewater treatment processes}

Compared with the other processes and data applied in this study, the selection of external processes of wastewater treatment was highly uncertain because no dataset exists specifically for wastewater from corn stover treatment. In addition, the contributions of wastewater treatment to eutrophication (freshwater, marine) and ecotoxicity were found extremely significant in some technological configurations as shown in Section 3.2. The choice of wastewater treatment process may thus significantly affect the results and conclusions of this study. This issue was addressed by performing a scenario sensitivity analysis using four different datasets for wastewater treatment as listed below. The mode values calculated from the distribution of each parameter were used as the basic values of the tested scenarios. Except for the external process of 
wastewater treatment, all the parameters, including biogas production and energy recovery from AD, remained identical for all the scenarios.

- Scenario A applied an external process for municipal wastewater treatment from the Ecoinvent database (treatment of wastewater, average, capacity $1 \times 10^{9} \mathrm{~L} / \mathrm{year}$ ). This process was the default external process applied in all assessments.

- Scenario B applied an external process from the Ecoinvent database representing the average wastewater treatment plant in the market, (market for wastewater, average). This process aimed at a general situation for wastewater treatment.

- Scenario $\mathrm{C}$ applied an external process from the Ecoinvent database for treating wastewater with a low level of pollutants (market for wastewater, unpolluted). Assuming that the effluent from the AD of the liquid residue from corn stover contains fewer pollutants than what is found in municipal wastewater, this process may appropriately represent the wastewater treatment.

- Scenario D assigned no external process of treating wastewater and no effluent (the biogas generation and energy recovery remained the same). With no wastewater treatment, this scenario represents a best case scenario because our inventory does not contain any information about the effluent content. In addition, no energy nor chemicals are used in the treatment. This scenario is no real alternative but a modelling step to assess the importance of wastewater treatment.

\section{Results and discussion}

Based on the parameter distribution from 'best-GWP' cases with the top $15 \%$ cumulative probability in terms of GWP, five levels of assessment were performed to reveal and compare the different process configurations for biorefining of corn stover to bioethanol in terms of (1) ethanol production and GWP, (2) environmental impact potentials in different categories, (3) the contribution of the main processes within a configuration to the different impact categories, (4) the global sensitivity analysis of parameters for different impact categories and (5) the probability analysis of integrated impact potentials. In addition, scenario sensitivity of wastewater treatment and process optimisation for alternative technologies are further discussed. The results provide a comprehensive understanding and potential guidance of a state-of-art biorefinery producing bioethanol, from an integrated environmental perspective.

\subsection{Ethanol production and GWPs for 'best-GWP' technologies}

Large variation in parameters within and across the technologies for bioethanol production was observed in our previous study with 141 individual datasets (Zhao et al., 2018). It has been verified that using parameter distribution can mitigate the effects of parameter outliers reported in individual cases and provide general understanding on the bioethanol production and environmental impacts of alternative technologies (Zhao et al., 2019). By selecting the datasets that encompass the best $15 \%$ of the probability 
distribution with respect to GWP, the parameter distribution can be narrowed in terms of GWP performance for the potential optimisation of each technological configuration. We believe that this method is a sound approach because focusing on the best parameter combinations to obtain the best results is common in any research and development activity. In this case the GWP performance is in focus as representing the best result.

Table 3 summarises the bioethanol production and carbon footprint of alternative technologies in terms

of 'best-GWP'. The full parameter distributions from the 141 datasets are available in our previous work (Zhao et al., 2019). The 'best-GWP' cases of all the alternative technologies showed significant savings ranging from -537 to $-1078 \mathrm{~kg} \mathrm{CO}$-eq $/ \mathrm{t}$ dry corn stover in average. Technological configurations with steam explosion and ammonia-based pretreatment seem the best in reducing carbon footprint of bioethanol production from corn stover. The bioethanol production was also improved by $3 \%$ to $15 \%$ for all the alternative technologies in the 'best-GWP' cases. Technological configurations with ammonia-based and alkaline pretreatment show the highest ethanol production per ton of corn stover, consistent with the results of the individual cases (Zhao et al., 2019).

Given that the purpose of bioethanol production is to substitute fossil fuel and thus reduce the global warming impacts, the balancing of ethanol production and the overall carbon footprint is the key question for the development of the bioethanol production technologies. However, the potential impacts on other environmental categories are also important given complex technologies, use of chemicals and enzymes and the exchange with the energy system.

Table 3 Bioethanol production and GWPs of alternative technologies in terms of best practice in GWP

\begin{tabular}{lll}
\hline Technological configuration & $\begin{array}{l}\text { Bioethanol production } \\
(\mathrm{kg} / \mathrm{t} \text { dry corn stover })\end{array}$ & $\begin{array}{l}\text { Carbon footprint } \\
\left(\mathrm{kg} \mathrm{CO}_{2} \text {-eq /t dry corn stover }\right)\end{array}$ \\
\hline S1-Acid & $149 \pm 39$ & $-796 \pm 42$ \\
S2-Alkaline & $195 \pm 35$ & $-772 \pm 39$ \\
S3-Solvent based & $175 \pm 67$ & $-548 \pm 202$ \\
S4-Steam explosion & $178 \pm 52$ & $-1078 \pm 166$ \\
S5-Liquid hot water & $148 \pm 28$ & $-537 \pm 55$ \\
S6-Ammonia based & $216 \pm 46$ & $-945 \pm 92$ \\
S7-Fungi & $155 \pm 24$ & $-742 \pm 36$ \\
\hline
\end{tabular}

3.2 Environmental impact potentials in 10 categories of the technological configurations with parameter distribution of 'best practice in GWP'

The normalised impacts of non-toxic and toxic categories with a 95\% confidence level are shown in box figures with mean and median values and standard deviations (Figures 2 and 3, respectively) for 'bestGWP' cases. The detailed histograms of Monte-Carlo simulation for each category and each configuration can be found in the Supplementary Information. 

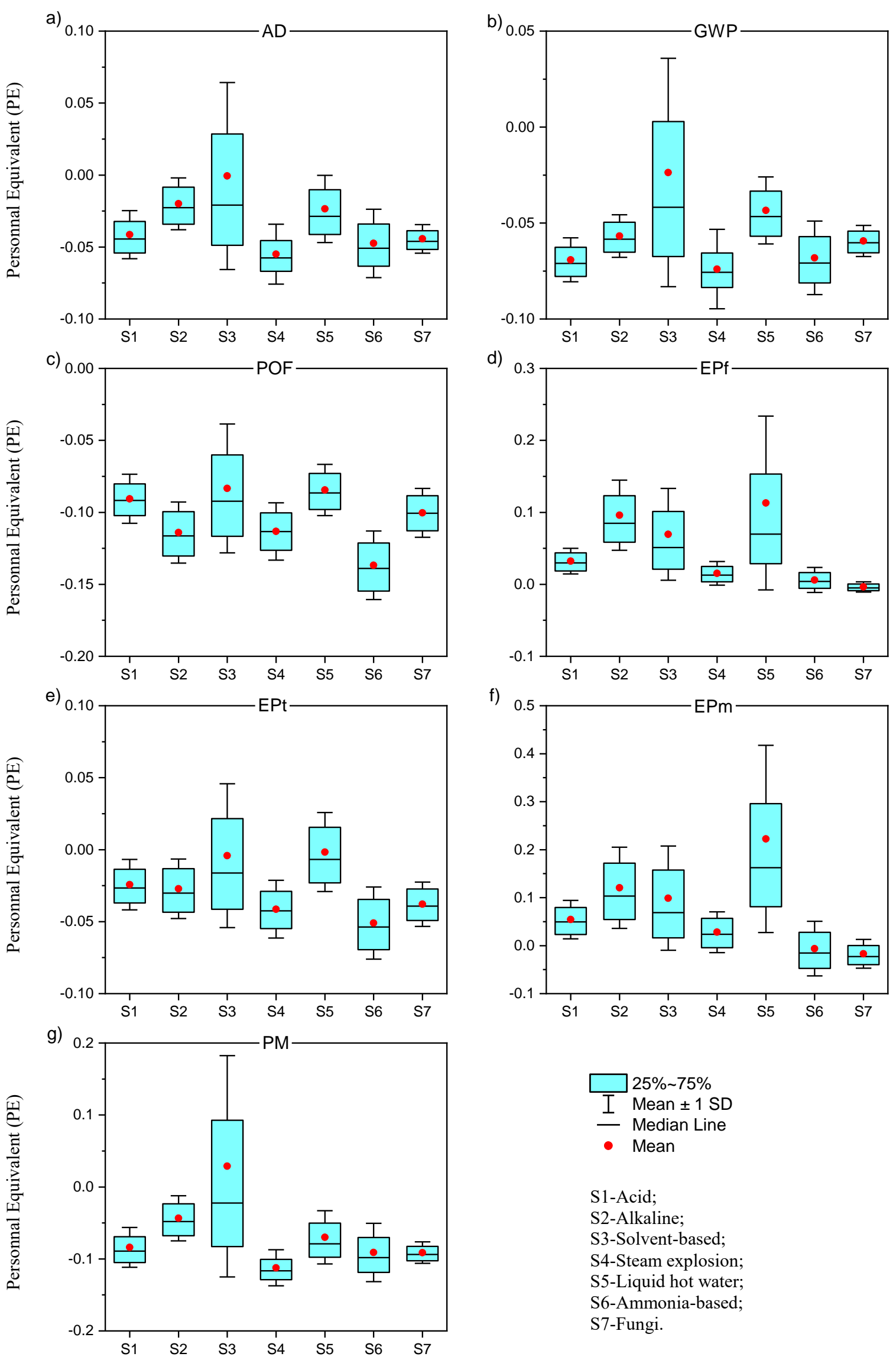

S1-Acid;

S2-Alkaline;

S3-Solvent-based;

S4-Steam explosion;

S5-Liquid hot water;

S6-Ammonia-based;

S7-Fungi.

Figure 2. Normalised environmental impact potentials in non-toxic categories of the seven 298 technological configurations with parameter distribution of 'best practice in GWP'. a) AD: acidification; b) 299 GWP: global warming potential; c) POF: photochemical ozone formation; d) EPf: eutrophication, 300 freshwater; e) EPt: eutrophication, terrestrial; f) EPm: eutrophication, marine; g) PM: particulate matter. 
In general, the normalised results (personal equivalents) of the toxic categories are numerically larger than the results of the non-toxic categories. However, ILCD assigns a different recommendation level to the toxic categories indicating less reliability due to associated uncertainty (Hauschild et al., 2013). The normalised results of non-toxic categories are moderate and all within the same order of magnitude (Figure 2). Thus, we chose to present the integrated environment impacts with non-toxic and toxic categories separately, as shown in Figures 2 and 3, respectively. Stratospheric ozone depletion and ionising radiation are not included because the personal equivalents of these two categories are marginal with at least one order of magnitude lower than the other categories (details can be found in the Supplementary Information).

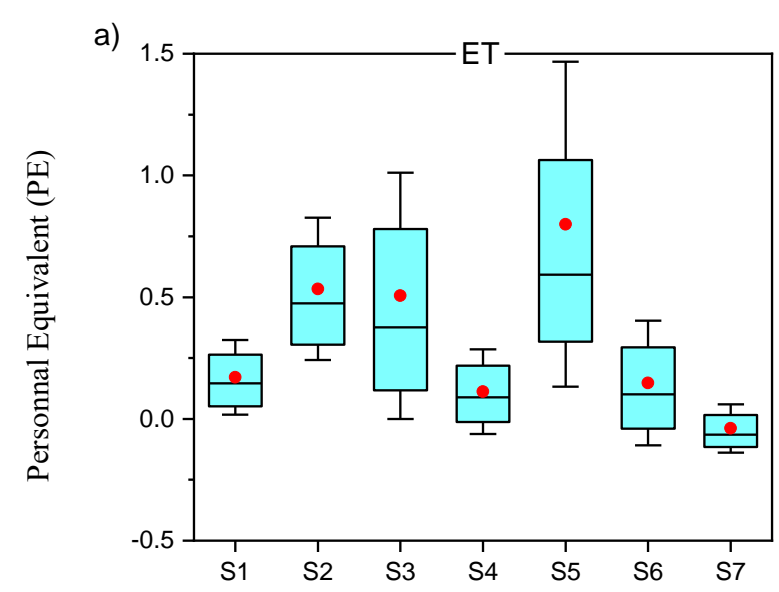

b)
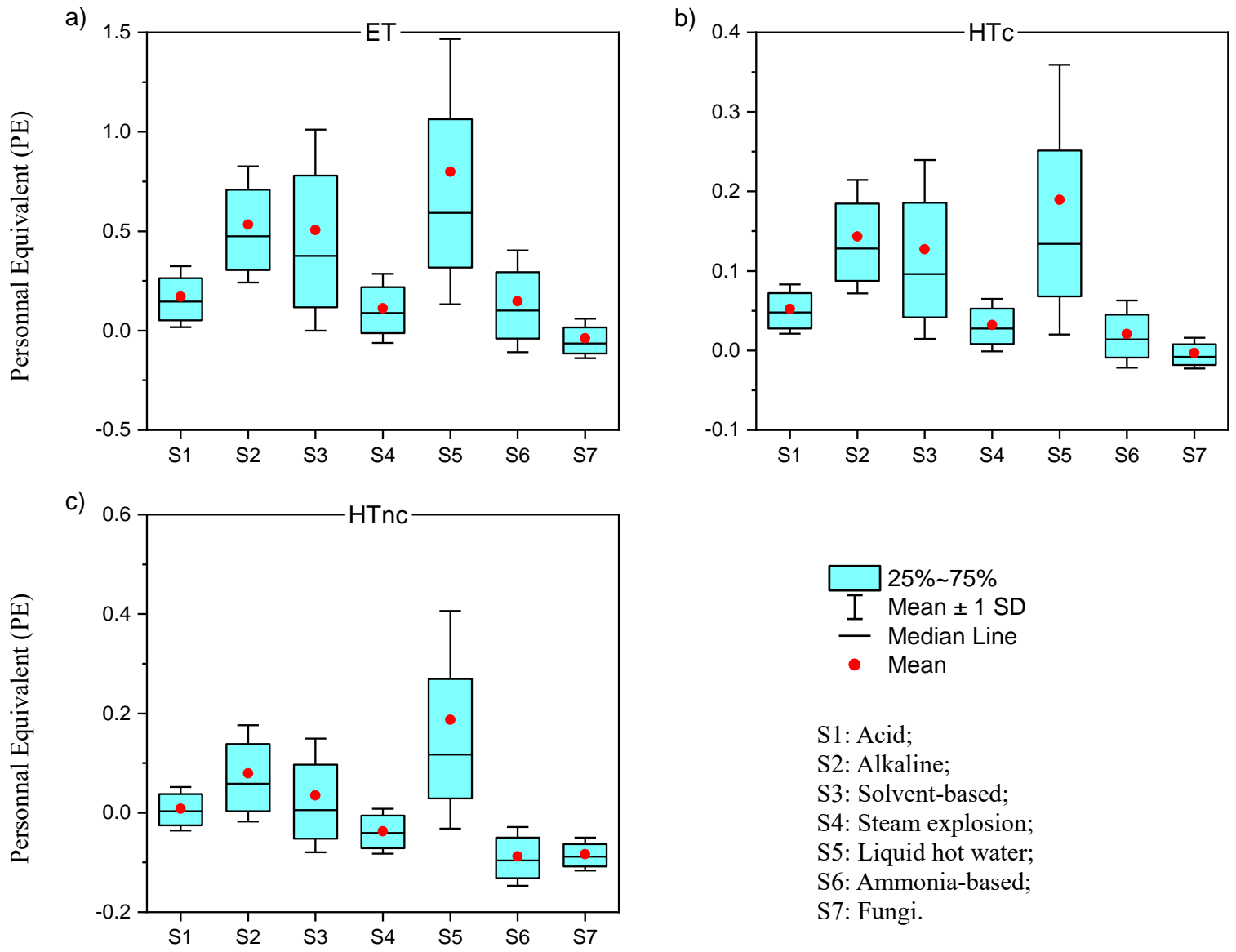

S1: Acid;

S2: Alkaline;

S3: Solvent-based;

S4: Steam explosion;

S5: Liquid hot water;

S6: Ammonia-based;

S7: Fungi.

Figure 3. Normalised environmental impact potentials in toxic categories of the seven technological configurations with parameter distribution of 'best practice in GWP'. a) ET: ecotoxicity, freshwater; b) HTc: human toxicity, cancer effects; c) HTnc: human toxicity, non-cancer effects.

Specifically, the normalised impacts in non-toxic categories show good environmental benefits for most categories and most configurations. This is mainly attributed to the net savings from ethanol substituting fossil fuel and energy recovered from the residues. An exception to this is the results of eutrophication to freshwater and eutrophication to marine water, which both show loads to the environment. Tracing back to the life cycle inventory, the potential adverse impacts to water environment are derived

318 from the discharged pollutants in the treated liquid residues. However, due to the lack of data in liquid 319 residue treatment during bioethanol production, the wastewater treatment used in all the scenarios was an 
external process for municipal wastewater treatment available in Ecoinvent (see Section 2.5). Of the same

321 reason, the potential impacts to ecotoxicity to freshwater are significantly higher than those to other

322 categories. The effects of the wastewater treatment are discussed in Section 3.6 based on the scenario sensitivity analysis. Among the technological configurations, S3 (solvent-based) show significant variations in most categories, and S5 (liquid hot water) display high variations in eutrophication to freshwater and eutrophication to marine and in the three toxic categories. The reason is that only a few very important parameters in S3 and S5 (e.g. solvent recovery ratio and enzyme consumption in hydrolysis) were optimised with the top $15 \%$ cumulative probability in terms of GWP, whereas some other parameters still held distributions with significant variation. This result contributed to the high variations in normalised impacts in the other categories.

\subsection{Process contribution to environmental impact potentials in $\mathbf{1 0}$ categories}

The contributions of individual processes within each technological configuration to the environmental impact potentials are shown in Figure 4 (detailed data with average values and deviations can be found in the Supplementary files of data source). In general, pretreatment, enzymatic hydrolysis, gasoline substitution with bioethanol, as well as solid and liquid residue treatment with energy recovery are major contributors to most impact categories. The other processes including transport and fragmentation, fermentation, distillation, water consumption and recycling, as well as solid waste disposal show insignificant contributions to the impact potentials because of low energy and material consumption and few emissions.

Particularly, pretreatment shows minor contributions to POF, EPt, EPm and HTnc, but significant contributions to $\mathrm{PM}, \mathrm{AD}, \mathrm{GW}$ and $\mathrm{ET}$. The reason is that its major impact to the environment is energy or material consumption rather than direct emissions. The environmental loads of pretreatment are significantly different between the technological configurations due to the diversity in pretreatment. Figures grouped in terms of environmental impact categories, for each technology configuration, can be found in the Supplementary Information. Huge amount of solvent consumption is the main reason for the loads of the technology based on solvent pretreatment (S3) to all the categories despite that the solvent recovery ratio has already been optimised with respect to GWPs. Enzymatic hydrolysis also contributes as a load to all the categories for all the technological configurations, especially to EPm and ET because of the life cycle inventory for enzyme production. Enzyme production data are scarce in literature but important for the results. It is supposed that, in full scale operations, the enzymes can be produced with a lower impact than what is seen for general enzyme datasets published. 

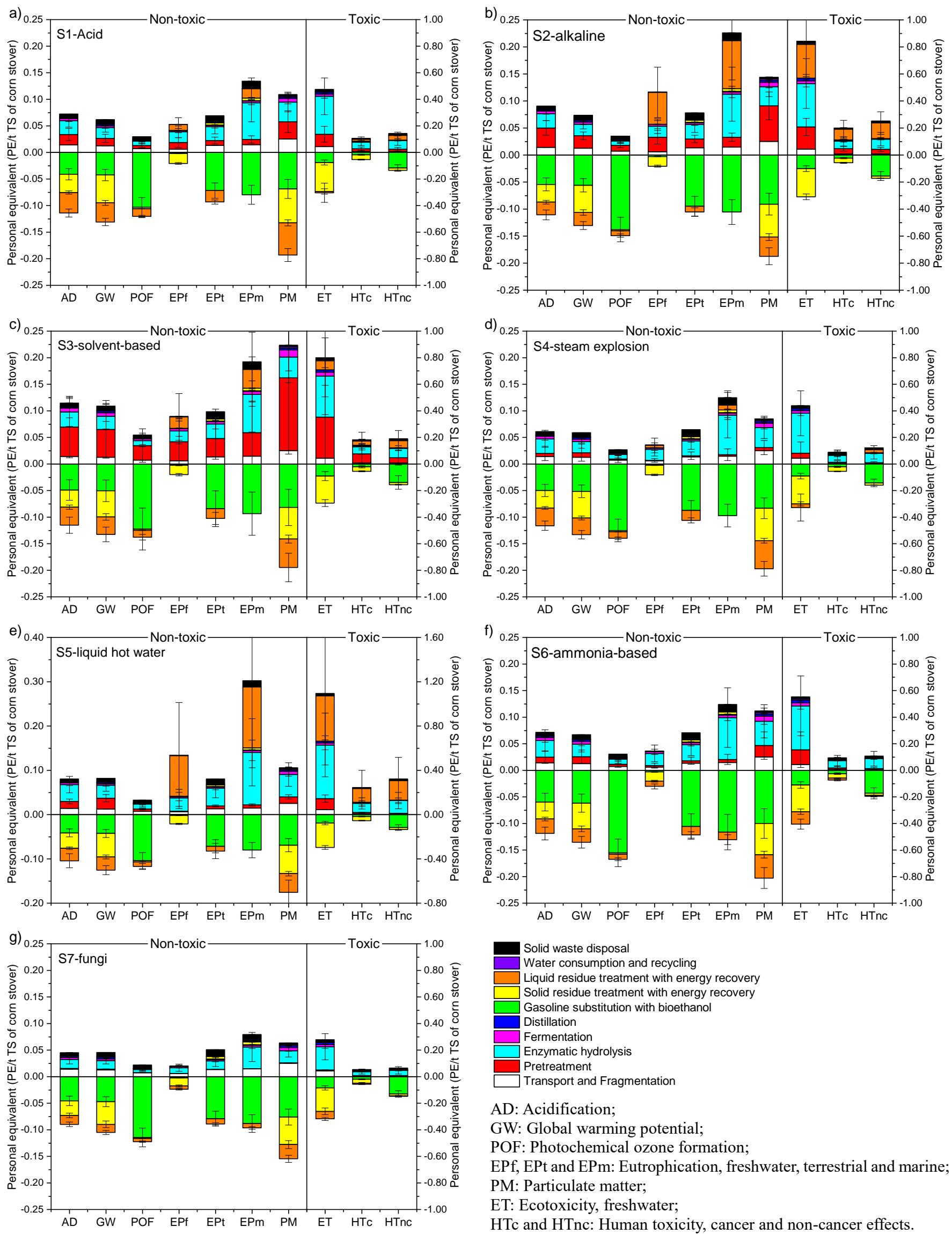

Figure 4. Process contribution to normalised environmental impact potentials in non-toxic and toxic 354 categories of the seven technological configurations. a) S1-Acid; b) S2-Alkaline; c) S3-Solvent-based; d) 355 S4-Steam explosion; e) S5-Liquid hot water; f) S6-Ammonia-based; g) S7-Fungi. (Please note that S5 uses 356 different axis scales from the others.) 
Gasoline substitution with bioethanol provides large savings in POF, EPt, EPm and HTnc. In addition, its contributions to the savings in $\mathrm{AD}, \mathrm{GW}$ and $\mathrm{PM}$ are moderate and comparable with those of energy recovery from solid and liquid residue treatment. All these savings are from avoiding production and utilisation of fossil fuel. Gasoline substation with bioethanol shows minimal impacts to EPf and HTc, attributed to the irrelevant or low emissions to be avoided.

Liquid residue treatment with energy recovery contributes to the savings in AD, GW, POF, EPt and PM to a certain extent. However, this process results in impact loads in EPf, EPm and ET in most technological configurations, especially in S2 (alkaline) and S5 (liquid hot water). The reason is that phosphate, nitrate and heavy metals from the wastewater treatment are potentially discharged into water environment. The significance of the wastewater treatment is discussed in Section 3.5.

The substance contribution to environmental impact potentials is provided in the Supplementary files of data source. The detailed data on impact potentials of each substance to each impact category were obtained with mode parameters for the seven technological configurations. In general, the impacts to AD, POF and EPt were mainly caused by nitrogen oxides. Meanwhile, the impacts to EPm and EPf were due to phosphate and nitrate, respectively. These substances were associated with energy consumption and substitution. The impacts to GWP and PM were attributed to $\mathrm{CO}_{2}$ (fossil) and particulates $(<2.5 \mu \mathrm{m}$ ), respectively, which were also related to energy consumption or substitution. By contrast, the potential impacts to ET, HTc and HTnc mainly originated from heavy metals to soil and water, including Zn, Cr and $\mathrm{Pb}$. These substances were mainly from wastewater treatment and energy and material consumption. All data were highly uncertain and the impact categories have relatively low recommendation levels.

Global sensitivity analysis was performed by combining the sensitivity of the results to the parameters and the uncertainty of each parameter. The results reveal how and which parameters affect the variance of the results. The distributions of some important parameters including conversion yields and chemical and enzyme consumptions had been narrowed into much lower variations than in their full distributions because the parameter distributions of 'best-GWP' were applied. In this instance, some parameters which had not been optimised according to GWPs now emerge in global sensitivity due to their high variations, including solid loadings in post wash (SL_PW), lignin and xylan yields to solid phase in pretreatment (LEF_PT and XEF_PT, respectively). The detailed results are available in the Supplementary Information. Solid loadings in post wash, pretreatment and hydrolysis become important, indicating that after process optimisation from global warming perspective, the side streams carrying huge amount of water should receive priority from the perspective of environmental impacts in further optimisation.

\subsection{Probability analysis of integrated impact potentials with Monte Carlo simulations}

The results within the different impact categories show that the different alternative configurations for bioethanol production from corn stover have highly different environmental impact potentials. For 
comparing across the technological alternatives, the normalised personal equivalents of the different impact categories are summed up for each round of Monte-Carlo simulation with equal weighting to present the integrated impact potentials of each technological configuration. The results are presented separately for non-toxic and toxic categories. On the basis of the 5000 Monte-Carlo simulations, the cumulative probabilities of the integrated impact potentials were obtained for each configuration, with a lognormal distribution in $95 \%$ confidence level (Figure 5, the histograms of distribution fitting are available in the Supplementary Information).
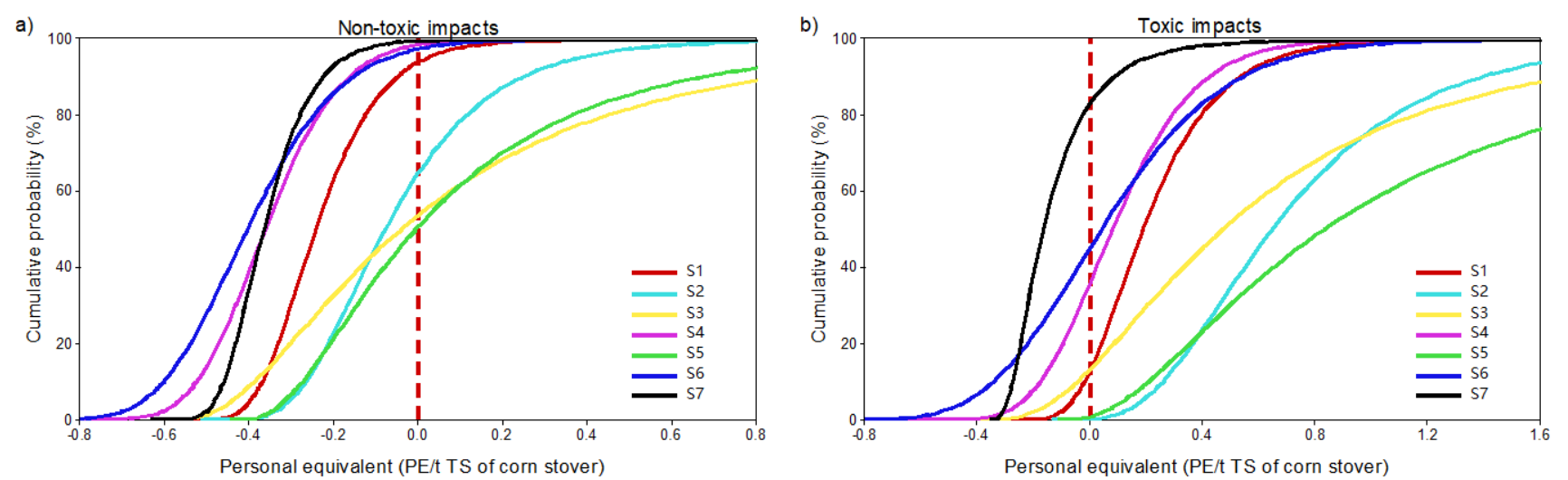

Figure 5. Cumulative probability of integrated impact potentials in a) non-toxic and b) toxic categories of the seven technological configurations. (S1-Acid; S2-Alkaline; S3-Solvent-based; S4-Steam explosion;

S5-Liquid hot water; S6-Ammonia-based; S7-Fungi.)

The integrated impact potentials of non-toxic categories were mainly negative for most configurations with probabilities of 50\%-100\%. This result indicates that producing ethanol from corn stover provides overall benefits to the environment when the GWP optimised (15\% best) technologies are used. Particularly, configurations S6 (ammonia-based), S4 (steam explosion) and S7 (fungi) are more likely than the other configurations to provide savings in impacts ( -0.8 to $-0.2 \mathrm{PE} / \mathrm{t}$ TS of corn stover) in non-toxic categories. This is attributed to more ethanol substitutions and less chemical and energy consumption according to the process contribution results (Figure 3). S7, S1 (acid) and S4 have relatively narrow distributions in nontoxic impacts because of their low variation in the parameters optimised according to 'best-GWP'. However, this fact also means that further improvement of these technologies will be limited and difficult. In addition, S5 (liquid hot water) and S3 (solvent-based) are likely to be less attractive in non-toxic impacts because of their very broad distributions.

In toxic impact categories, the integrated impact potentials are negative for only S7, S6 and S4, with probabilities of $40 \%-80 \%$. S7 has the highest probability for avoiding toxic impacts because of very limited 


\subsection{Scenario sensitivity analysis of wastewater treatment process}

As suggested by the biorefinery framework proposed by NREL, USA (Tao et al., 2017), we assume that the liquid residues separated from the bioethanol processes is treated by AD with energy recovery from the generated biogas. The details on the $\mathrm{AD}$ process and biogas utilisation are described in the Supplementary Information. However, because of lacking accurate data for liquid residue treatment in bioethanol production, a life cycle inventory for the wastewater treatment process was selected from the Ecoinvent database (Ecoinvent, 2016), as described previously. However, this wastewater treatment process appeared to be crucial to the integrated environmental impacts according to the process contribution results discussed previously.

Figure 6 shows the changes of integrated impact potentials in terms of the different options in wastewater treatment process, introduced by using three different options for wastewater treatment (details in the Supplementary Information) and one unrealistic option modelled with no energy consumption or effluent from wastewater treatment. In the technological configuration S5, which uses huge amount of water for pretreatment and postwash, wastewater treatment presented significant sensitivity to the integrated environmental impacts of both non-toxic and toxic categories. By contrast, the results with different processes of wastewater treatment are quite stable for S6 and S7 because of the minimum water consumption during pretreatment with no need for postwash. In general, wastewater treatment processes indicate more significant sensitivity to toxic impacts than to non-toxic impacts.
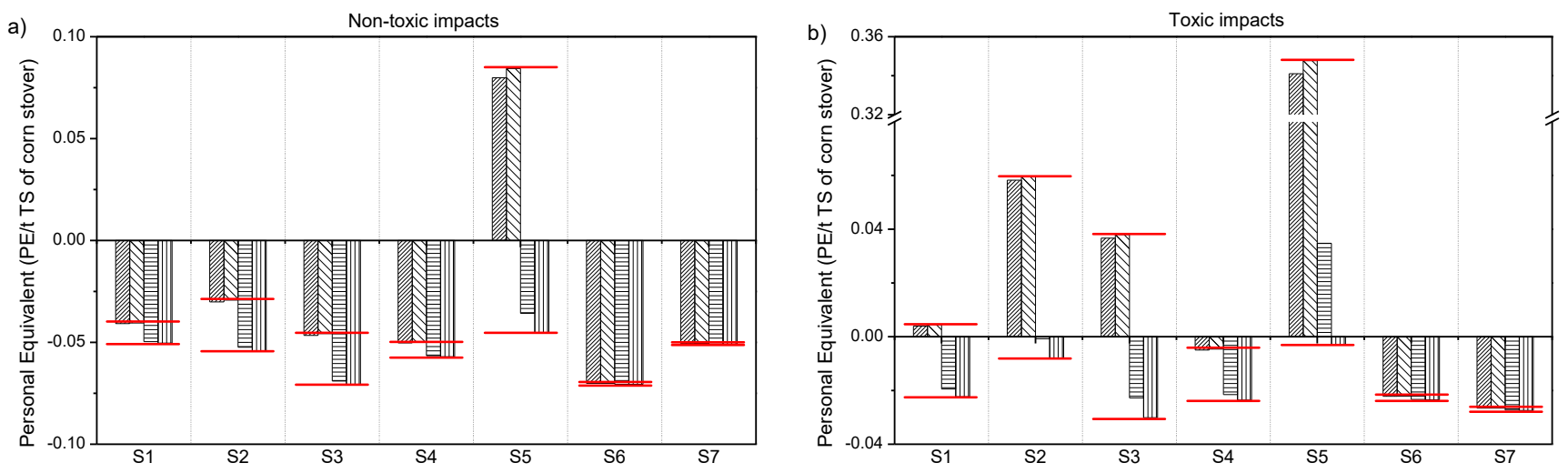

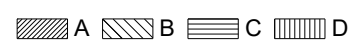

Figure 6. Normalised environmental impact potentials with different wastewater treatment processes in a) non-toxic and b) toxic categories of the seven technological configurations. See text for explanation of wastewater treatment options A: treatment of wastewater, average, capacity $1 \times 10^{9} \mathrm{~L} /$ year; B: market for wastewater, average; $\mathrm{C}$ : market for wastewater, unpolluted; D: modelled as no energy consumption or effluent. (S1-Acid; S2-Alkaline; S3-Solvent-based; S4-Steam explosion; S5-Liquid hot water; S6Ammonia-based; S7-Fungi. Red lines show the maximum and minimum ranges) 
Shifting the wastewater treatment options from Scenarios A and B to Scenarios C and D can sometimes change the ranking of the technologies according to their sensitivities, especially for the technological configuration S3. Therefore, accurate data with little uncertainty regarding the wastewater treatment is desirable for reducing the uncertainty of the technology comparison. However, the technological configurations S6, S4 and S7, which were identified in the previous section as promising in avoiding environmental impacts, still perform satisfactorily with different options of wastewater treatment process.

\subsection{Process optimisation for alternative technologies}

According to the probability perspective of the integrated environmental impacts, only some technologies are of interest for further development. However, technological selection is a comprehensive task that must pay attention to the yield of bioethanol obtained, the environment impacts, economy, and the technological feasibility and robustness. The comparison of the technological alternatives for bioethanol production from corn stover was for the first time made in the current study by quantitatively integrating the performance with respect to ethanol production, GWP and overall environmental performance from a statistical perspective. Suggestions for technology optimisation were also provided according to their global sensitivity to the integrated environmental impacts. The outcome is summarised below, where we also offer our views on prioritising the technological alternatives for further development:

- S1: Technological configuration with acid pretreatment, medium priority. This technology has been studied extensively, but its ethanol production is low, and its performance in GWP reduction is just fair. It performs fair with respect to non-toxic impacts and poor with respect to toxic impacts. However, optimisation of water consumption (solid loading) in all the processes, enzyme and acid consumption, and xylose recovery in pretreatment has room for improvement.

- S2: Technological configuration with alkaline pretreatment, medium priority. This technology has a high ethanol production and a fair to good performance in GWP reduction. It performs fair with respect to non-toxic impacts but is not satisfying with respect to toxic impacts. This technology has great room for improvement, including optimization of enzyme and alkaline consumption as well as water consumption (solid loading) in all the processes.

- S3: Technological configuration with solvent-based pretreatment, low priority. This technology has a fair ethanol production. However, the GWP reduction performance is poor due to its use of solvent in spite of the high solvent recovery. The result shows high uncertainty with respect to almost all the environmental impacts. In addition, the average performance is not satisfying enough. The major concerns 
in further study include optimisation of water consumption (solid loading) in all processes, solvent recovery and enzyme consumption.

- S4: Technological configuration with steam explosion, high priority. This technology is fairly good in both ethanol production and GWP reduction. This technology is also good in avoiding non-toxic impacts and fair with respect to toxic impacts. Technological optimisation should focus on lignin conversion in pretreatment, enzyme consumption and solid loadings during the process.

- S5: Technological configuration with liquid hot water pretreatment, low priority. This technology performs poorly in both ethanol production and GWP reduction. Particularly, this technology shows high uncertainty with respect to almost all the environmental impacts, and the average performance is poor. The water and enzyme consumption during postwash and hydrolysis as well as the overall ethanol production require significant improvement for further optimisation.

- S6: Technological configuration with ammonia-based pretreatment, high priority. This technology produces a high amount of ethanol and performs well in GWP reduction. This technology is also good at avoiding non-toxic impacts and fair with respect to the toxic impacts. Optimisation of this technology should focus on lignin conversion in pretreatment, enzyme consumption and ammonia recycling.

-S7: Technological configuration with fungi pretreatment, medium priority. This technology performs poorly in ethanol production, and its performance in GWP reduction is fair. However, after optimization, this technology can be good at avoiding integrated non-toxic and toxic impacts, but the room for improvement is considered limited. Further optimisation should focus on enzyme consumption and solid loadings in hydrolysis.

In general, technological configurations S4 and S6 seem to have potential for further technological development and application according to the available data from laboratory experiments reported in scientific literature. S1, S2 and S7 may have potential but further research on the abovementioned key issues should be undertaken. However, $\mathrm{S} 3$ and $\mathrm{S} 5$ do not seem attractive from an environmental perspective, including GWP and integrated non-toxic and toxic categories. These two technologies require substantial improvements at the laboratory scale before they can be considered for technological development and practical application.

\section{Conclusions}

The potential environmental impacts, namely, climate change (global warming potential), stratospheric ozone depletion, acidification, eutrophication (terrestrial), eutrophication (freshwater), eutrophication (marine), photochemical ozone formation (human health), ecotoxicity (freshwater), human toxicity (cancer effects), and human toxicity (non-cancer effects), of producing bioethanol from corn stover were systematically assessed by LCA for selected relevant experimental datasets reported in literature. The $15 \%$ best datasets with respect to savings in GWP for seven different technological configurations were 
extracted from recently reviewed 474 publications on converting corn stover to bioethanol. These datasets

518 were considered relevant for developing technologies of bioethanol production from corn stover because

519 of the overall purpose to reduce the greenhouse gas footprint of fuel consumption by amending gasoline

520 with bioethanol. The assessed impacts were complex and included both loads to the environment (positive

521 numbers) and savings to the environment (negative values), generally from $-0.1 \mathrm{PE}$ to $0.1 \mathrm{PE}$ per $\mathrm{t}$ of dry

522 corn stover for most non-toxic impact categories. In general, the technologies with pretreatment using

523 solvent (S3) or liquid hot water (S5) had the highest environmental loads and the highest uncertainty due

524 to the high solvent consumption and water and energy consumption, respectively. The toxic impacts with

$525-0.2 \mathrm{PE}$ to $0.5 \mathrm{PE}$ per $\mathrm{t}$ of dry corn stover were in general higher than the non-toxic impacts, but this result

526 was consistent across technologies. The fossil fuel substitution with bioethanol provided environmental

527 savings, and so did the energy recovered from the liquid and the solid residues. Meanwhile, the production

528 of the enzymes used for most technologies was a significant load to the environment. Each process

529 throughout the whole technology shows different sensitivities to different environmental impact categories.

530 The effluent from the anaerobic digestion treating the liquid residue was not well characterised in the

531 datasets available and should receive considerable attention in future development work. The reason is that

532 our analysis indicates that the effluent treatment and discharge in nearly all the technologies could be a

533 significant load to the environment and particularly important to toxic impacts. Based on cumulative

534 probabilities of the overall environmental performance together with the amount of bioethanol produced,

535 we consider the technologies with pretreatment by using steam explosion (S4) or ammonia (S6) as the

536 highest priority for further development with approximately $100 \%$ and $40 \%$ probabilities to have savings

537 in non-toxic and toxic impacts, respectively. By contrast, the technologies with pretreatment by using

538 solvents (S3) or liquid hot water (S5) have the lowest priorities with only $50 \%$ and less than $10 \%$

539 probabilities to have savings in non-toxic and toxic impacts, respectively. The technologies with

540 pretreatment by using acids (S1), alkali (S2) and fungi (S7) are of medium priority because they need

541 significant improvements either in their bioethanol yield or environmental performance. From this point of

542 view, the technologies with steam explosion and ammonia pretreatment should receive priority in

543 development of technology for producing bioethanol from corn stover. Lignin conversion in pretreatment,

544 enzyme consumption, solid loadings during the process and chemical recycling are suggested to be

545 carefully optimized during industrial application from a sustainability perspective. In addition, we suggest

546 that assessment of the potential environmental impacts to be an integrated part of the further research and

547 development for producing bioethanol from corn stover in order to ensure the development of sustainable 548 technologies.

\section{Conflicts of interest}

551 The authors declare no conflicts of interest. 


\section{Acknowledgements}

\section{Electronic Supplementary Information}

Electronic Supplementary Information associated with this article can be found in the online version: system boundary; parameter distribution of the top 15\% 'best-GWP' cases; histograms of Monte-Carlo simulation; selected external processes of wastewater treatment; process contribution to environmental impact potentials; sensitivity coefficients of parameters; global sensitivity analysis of parameters; uncertainty contribution of parameters; original sources of the extracted datasets; data of process contributions to each impact category; data of impacts in terms of substance with mode parameters.

\section{Reference}

Abo, B. O., Gao, M., Wang, Y. L., Wu, C. F., Ma, H. Z., Wang, Q. H., 2019. Lignocellulosic biomass for bioethanol: an overview on pretreatment, hydrolysis and fermentation processes. Reviews on Environmental Health, 34(1), 57-68.

Bairamzadeh, S., Saidi-Mehrabad, M., Pishvaee, M. S., 2018. Modelling different types of uncertainty in biofuel supply network design and planning: A robust optimization approach. Renewable Energy, 116, 500-517.

Bisinella, V., Conradsen, K., Christensen, T. H., Astrup, T. F., 2016. A global approach for sparse representation of uncertainty in Life Cycle Assessments of waste management systems. International Journal of Life Cycle Assessment, 21(3), 378-394.

Capolupo, L., Faraco, V., 2016. Green methods of lignocellulose pretreatment for biorefinery development. Applied Microbiology and Biotechnology, 100(22), 9451-9467.

Chang, F. C., Lin, L. D., Ko, C. H., Hsieh, H. C., Yang, B. Y., Chen, W. H., Hwang, W. S., 2017. Life cycle assessment of bioethanol production from three feedstocks and two fermentation waste reutilization schemes. Journal of Cleaner Production, 143, 973-979.

Clavreul, J., Baumeister, H., Christensen, T. H., Damgaard, A., 2014. An environmental assessment system for environmental technologies. Environmental Modelling \& Software, 60, 18-30.

da Silva, A. R. G., Giuliano, A., Errico, M., Rong, B. G., Barletta, D., 2019. Economic value and environmental impact analysis of lignocellulosic ethanol production: assessment of different pretreatment processes. Clean Technologies and Environmental Policy, 21(3), 637-654. 
Dutta, K., Daverey, A., Lin, J. G., 2014. Evolution retrospective for alternative fuels: First to fourth generation. Renewable Energy, 69, 114-122.

Ecoinvent. (2016). "Ecoinvent database." Retrieved 2016, from http://ecoinvent.com.

Farahani, S. S., Asoodar, M. A., 2017. Life cycle environmental impacts of bioethanol production from sugarcane molasses in Iran. Environmental Science and Pollution Research, 24(28), 22547-22556.

Guerrero, A. B., Munoz, E., 2018. Life cycle assessment of second generation ethanol derived from banana agricultural waste: Environmental impacts and energy balance. Journal of Cleaner Production, 174, 710-717.

Hauschild, M. Z., Goedkoop, M., Guinee, J., Heijungs, R., Huijbregts, M., Jolliet, O., Margni, M., De Schryver, A., Humbert, S., Laurent, A., Sala, S., Pant, R., 2013. Identifying best existing practice for characterization modeling in life cycle impact assessment. International Journal of Life Cycle Assessment, 18(3), 683-697.

Hong, J. M., Zhou, J., Hong, J. L., 2015. Comparative study of life cycle environmental and economic impact of corn- and corn stalk-based-ethanol production. Journal of Renewable and Sustainable Energy, 7(2), 16.

Jung, K. A., Lim, S. R., Kim, Y., Park, J. M., 2017. Opportunity and challenge of seaweed bioethanol based on life cycle CO2 assessment. Environmental Progress \& Sustainable Energy, 36(1), 200-207.

Kumar, R., Tabatabaei, M., Karimi, K., Horvath, I. S., 2016. Recent updates on lignocellulosic biomass derived ethanol - A review. Biofuel Research Journal-Brj, 3(1), 347-356.

Laurent, A., Hauschild, M. Z., Golsteijn, L., Simas, M., And, J. F., Wood, R., 2013. Deliverable 5.2: Normalisation factors for environmental, economic and socio-economic indicators. Project: Development and application of a standardized methodology for the prospective sustainability assessment of technologies. Copenhagen.

Loow, Y. L., Wu, T. Y., Jahim, J. M., Mohammad, A. W., Teoh, W. H., 2016. Typical conversion of lignocellulosic biomass into reducing sugars using dilute acid hydrolysis and alkaline pretreatment. Cellulose, 23(3), 1491-1520.

Mandegari, M. A., Farzad, S., Gorgens, J. F., 2017. Economic and environmental assessment of cellulosic ethanol production scenarios annexed to a typical sugar mill. Bioresource Technology, 224, 314-326.

Morales, M., Quintero, J., Conejeros, R., Aroca, G., 2015. Life cycle assessment of lignocellulosic bioethanol: Environmental impacts and energy balance. Renewable \& Sustainable Energy Reviews, 42, 1349-1361.

Mullins, K. A., Griffin, W. M., Matthews, H. S., 2011. Policy implications of uncertainty in modeled lifecycle greenhouse gas emissions of biofuels. Environmental Science \& Technology, 45(1), 132-138.

Murphy, C. W., Kendall, A., 2015. Life cycle analysis of biochemical cellulosic ethanol under multiple scenarios. Global Change Biology Bioenergy, 7(5), 1019-1033. 
Neupane, B., Konda, N., Singh, S., Simmons, B. A., Scown, C. D., 2017. Life-cycle greenhouse gas and water intensity of cellulosic biofuel production using cholinium lysinate ionic liquid pretreatment. Acs Sustainable Chemistry \& Engineering, 5(11), 10176-10185.

Olofsson, J., Barta, Z., Borjesson, P., Wallberg, O., 2017. Integrating enzyme fermentation in lignocellulosic ethanol production: life-cycle assessment and techno-economic analysis. Biotechnology for Biofuels, 10,14 .

Pourhashem, G., Adler, P. R., McAloon, A. J., Spatari, S., 2013. Cost and greenhouse gas emission tradeoffs of alternative uses of lignin for second generation ethanol. Environmental Research Letters, 8(2), 13.

Rathnayake, M., Chaireongsirikul, T., Svangariyaskul, A., Lawtrakul, L., Toochinda, P., 2018. Process simulation based life cycle assessment for bioethanol production from cassava, cane molasses, and rice straw. Journal of Cleaner Production, 190, 24-35.

Soam, S., Kapoor, M., Kumar, R., Borjesson, P., Gupta, R. P., Tuli, D. K., 2016. Global warming potential and energy analysis of second generation ethanol production from rice straw in India. Applied Energy, 184, 353-364.

Solarte-Toro, J. C., Romero-Garcia, J. M., Martinez-Patino, J. C., Ruiz-Ramos, E., Castro-Galiano, E., Cardona-Alzate, C. A., 2019. Acid pretreatment of lignocellulosic biomass for energy vectors production: A review focused on operational conditions and techno-economic assessment for bioethanol production. Renewable \& Sustainable Energy Reviews, 107, 587-601.

Spatari, S., Bagley, D. M., MacLean, H. L., 2010. Life cycle evaluation of emerging lignocellulosic ethanol conversion technologies. Bioresource Technology, 101(2), 654-667.

Tao, L., Markham, J. N., Haq, Z., Biddy, M. J., 2017. Techno-economic analysis for upgrading the biomassderived ethanol-to-jet blendstocks. Green Chemistry, 19(4), 1082-1101.

Trivedi, P., Malina, R., Barrett, S. R. H., 2015. Environmental and economic tradeoffs of using corn stover for liquid fuels and power production. Energy \& Environmental Science, 8(5), 1428-1437.

Wojtusik, M., Zurita, M., Villar, J. C., Ladero, M., Garcia-Ochoa, F., 2016. Influence of fluid dynamic conditions on enzymatic hydrolysis of lignocellulosic biomass: Effect of mass transfer rate. Bioresource Technology, 216, 28-35.

Zabed, H., Sahu, J. N., Boyce, A. N., Faruq, G., 2016. Fuel ethanol production from lignocellulosic biomass: An overview on feedstocks and technological approaches. Renewable \& Sustainable Energy Reviews, $66,751-774$.

Zhao, Y., Damgaard, A., Christensen, T. H., 2018. Bioethanol from corn stover - a review and technical assessment of alternative biotechnologies. Progress in Energy and Combustion Science, 67, 275-291.

Zhao, Y., Damgaard, A., Xu, Y., Liu, S., Christensen, T. H., 2019. Bioethanol from corn stover - Global warming footprint of alternative biotechnologies. Applied Energy, 247, 237-253. 
656 Zhu, L. J., Guo, W. W., Yin, S., Wang, S. R., 2015. Comparative life cycle assessment of ethanol synthesis 657 from corn stover by direct and indirect thermochemical conversion processes. Energy \& Fuels, 29(12), 658 7998-8005.

659 Zucaro, A., Forte, A., Fierro, A., 2018. Life cycle assessment of wheat straw lignocellulosic bio-ethanol 660 fuel in a local biorefinery prospective. Journal of Cleaner Production, 194, 138-149. 